\title{
COMPARATIVE HEMOGLOBIN AND HEMATOCRIT BEFORE AND AFTER DONATION TO BLOOD DONATE IN UNIT TRANSFUSION YOGYAKARTA CITY
}

\author{
Yuli Astuti ${ }^{\mathrm{a}^{*}}$, Dyah Artini ${ }^{\mathrm{b}}$ \\ ${ }^{a, b}$ Universitas Jenderal Achmad Yani Yogyakarta ; Yogyakarta 55293 ; Indonesia
}

\begin{abstract}
Blood is one of the main components in the human body. The people's need for blood is high, therefore the blood service in Indonesia should have good quality and total services. Unit Transfusion Yogyakarta City is one of the good services in the blood donation. In the blood donation, examination hemoglobin and hematocrit are important to selection for donors. The aim of this study is to determine comparative in hemoglobin and hematocrit levels before and after donors in UTD PMI Yogyakarta City. The type of research used was experimental with cross sectional research design. The sampling technique used was accidental sampling with a total sample of 67 donors. Based on the results of statistical tests on the data obtained, the results obtained with $p$ value $<0,05$ which is significantly different between the hemoglobin level before and after the donor. Based on these result there were differences in hemoglobin and hematocrit levels before and after of blood donation in Unit Transfusion PMI Yogyakarta City.
\end{abstract}

Keywords: hemoglobin level ; hematocrit level ; after and before blood donation

\section{Introduction}

Blood is one of the main components in the human body. The demand blood and blood product are high, therefore blood services and blood donation have to improved.

Some result of research explain, demand blood transfusion increase. Blood product example is red cell can be repair condition due to more complex surgical procedures, transplantations, hematology and oncology for which need transfusions (Maurens Julie et all, 2016).

The purpose of donor selection is to assess the suitability of an individual to be a blood donor so that blood donation is safe for the donor and the blood products derived from this donation are safe for the recipients. The donor selection process should be carried out in accordance with written standard operating procedures (WHO, 2012).

Someone want to blood donation, have to pass hemoglobin and hematocrit examination.
Someone have to normal hemoglobin and hematocrit normal condition (WHO, 2012). Hemoglobin and hematocrit examination is one of procedure have to passed examination if someone want to donation (Mast Alan, 2015). Minimum hemoglobin level to blood donation is $12.5 \mathrm{gr} / \mathrm{dl}-17 \mathrm{gr} / \mathrm{dl}$. And hematocrit level to donation is $34.9-44.5 \%$ for women and $38.8-50 \%$ for men (Speencer Bryan et all, 2016). After donation $\pm 350 \mathrm{cc}-450$ cc somebody will be decrease hemoglobin and hematocrit. Recovery of hemoglobin, ferritin and hematocrit 59 days after donation (Potgeisser, 2008).

In the Unit Transfusion Yogyakarta city, after donation donor will be given iron tablet to repair hemoglobin and hematocrit level. Therefore, the aims of the present study were: (1) To investigate hemoglobin and hematocrit level before donation. (2) To investigate hemoglobin and hematocrit level after donation. (3) To investigation comparative hemoglobin and hematocrit level before and after donation.

\footnotetext{
*) Corresponding Author (Yuli Astuti)

E-mail: astuti_yuli35@yahoo.co.id
} 


\section{Method}

Subject this study is donor in the Unit Transfusion PMI Yogyakarta city ( $\mathrm{n}=67$ donors) technique sampling used accidental sampling to take cases or respondents who happen to be available or available and cross sectional research design.

All participants provided written informed consent after explaining all potential risks of the study and the right to withdraw at any time. The study was approved by the Ethics Committee of the Jenderal Achmad Yani Yogyakarta University.

This study hemoglobin and hematocrit level measurement before and after donation used hemoglobin checker (EKF fotometri).

Statistic analyses this study used univariate analyses and bivariate analyses. Univariate analyses used distribution frequencies, and bivariate analyses used T-test. When appropriate, contrast analyses were performed to compare means. Statistical significance was set at $\mathrm{p}<0.05$.

\section{Result and Discussion}

\section{Characteristic Respondent}

The results of the study are based on the characteristics of respondents viewed from table 1 .

Table 1. Characteristic Respondents.

\begin{tabular}{lcc}
\hline \multicolumn{1}{c}{ Characteristic } & $\mathrm{N}$ & $\%$ \\
\hline Sex & & \\
Male & 42 & 62.7 \\
Female & 25 & 37.3 \\
Age & & \\
$15-25$ & 29 & 43.3 \\
$26-35$ & 20 & 29.8 \\
$36-45$ & 15 & 22.4 \\
$46-60$ & 3 & 4.5 \\
Level of Education & & \\
SD & 10 & 14.9 \\
SMP & 15 & 22.38 \\
SMA & 17 & 25.37 \\
S1/Diploma & 25 & 37.35 \\
\hline
\end{tabular}

Based table 1 result this study, respondent, based on sex male more than female, based on age is youngest 15 years, and the oldest respondent is 60 years, and based on level of education most of them is S1/Diploma (37.35\%). Result analyses univariate hemoglobin and hematocrit before blood donation seen table 2 .
Table 2. Hemoglobin and Hematocrit Level Before Blood Donation.

\begin{tabular}{lcccc}
\hline \multicolumn{1}{c}{ Before Donation } & $\mathrm{N}$ & $\%$ & Mean & $\begin{array}{c}\text { Std. } \\
\text { Def }\end{array}$ \\
\hline $\begin{array}{l}\text { Hemoglobin } \\
\text { (gr/dl) }\end{array}$ & & & 14.7 & 0.16 \\
$12.6-14$ & 20 & 29.8 & & \\
$14,1-15.5$ & 33 & 49.2 & & \\
$15.6-17$ & 14 & 21 & & \\
& 67 & 100 & & \\
Hematocrit (\%) & & & 44 & 014 \\
$36-40$ & 7 & 10.45 & & \\
$41-45$ & 42 & 62.68 & & \\
$46-50$ & 18 & 26.75 & & \\
& 67 & 100 & & \\
\hline
\end{tabular}

Result analyses univariate hemoglobin and hematocrit after blood donation seen table 3 :

Table 3. Hemoglobin and Hematocrit Level After Blood Donation.

\begin{tabular}{lcccc}
\hline \multicolumn{1}{c}{ After Donation } & $\mathrm{N}$ & $\%$ & Mean & Std. Def \\
\hline $\begin{array}{l}\text { Hemoglobin } \\
\text { (gr/dl) }\end{array}$ & & & 13.8 & 0.16 \\
$12.6-14$ & 9 & 13.4 & & \\
$14,1-15.5$ & 22 & 32.8 & & \\
$15.6-17$ & 36 & 53.7 & & \\
& 67 & 100 & & \\
Hematocrit (\%) & & & 41.5 & \\
$36-40$ & 22 & 34.3 & & \\
$41-45$ & 35 & 52.2 & & \\
$46-50$ & 9 & 13.4 & & \\
& 67 & 100 & & \\
\hline
\end{tabular}

Result comparative hemoglobin and hematocrit before and after blood donation seen table 4.

Table 4. Comparative Hemoglobin and Hematocrit Before and After Blood Donation.

\begin{tabular}{lcc} 
& Before Donation & After Donation \\
Mean & 14.6880597 & 13.84626866 \\
Variance & 1.187734057 & 2.368584351 \\
Observations & 67 & 67 \\
Pooled Variance & 1.778159204 & \\
Hypothesized & & \\
Mean Difference & 0 & \\
Df & 132 & \\
$\mathrm{t}$ Stat & 3.653771499 & \\
$\mathrm{P}(\mathrm{T}<=\mathrm{t})$ one-tail & 0.000185826 & \\
$\mathrm{t}$ Critical one-tail & 1.65647927 & \\
$\mathrm{P}(\mathrm{T}<=\mathrm{t})$ two-tail & 0.000371652 & \\
$\mathrm{t}$ Critical two-tail & 1.978098814 & \\
\hline
\end{tabular}

Based on table 4 seen $P$-value $<0.05$ this is statistically shows that there are differences 
hemoglobin and hematocrit between before and after blood donation.

Based on the bivariate analyses, it was found that there was a difference between hemoglobin and hematocrit before and after blood donation. Donating blood regularly can reduce hemoglobin and hematocrit levels. But blood hemoglobin is not only influenced by the frequency of blood donors. This decrease in hemoglobin levels is due to a decrease in iron levels in the blood. This decreased level of hemoglobin causes donor anemic conditions after blood donation. The frequency with which anemia is most frequent after donors occurs in women (Angelique et all, 2017).

Donors will be reduced by $25 \%-35 \%$, and will restore recovery or add iron after 8 weeks or 2 months. This will cause hemoglobin levels after the donor which will cause some side effects after the donor is fatigue, and sometimes starts to push (Joseph et al, 2015).

Maximum reduction in hematocrit is $10 \%$, blood donation can reduce hematocrit and blood viscosity so as to prevent cardiovascular disease (Sudipta, 2016).

\section{Conclusion and Suggestion}

The conclusion the study is there is a difference between hemoglobin levels before and after donors in blood donation at Unit Transfusion PMI Yogyakarta City. Statistic seen P-Value ( $\mathrm{p} \quad$ <.005). Suggestion to respondent/donors hopefully It is expected to keep donating blood, but it is balanced by maintaining a diet, reducing salt consumption, exercising, and reducing smoking. Suggestion for PMI and the Health Office, to provide information to the public about blood donation.

\section{Acknowledgements}

I would express my gratitude for Faculty of Health Jenderal Achmad Yani Yogyakarta University, Unit PPPM Jenderal Achmad Yani Yogyakarta University, Kopertis region V Yogyakarta.

\section{References}

Angelique et all. 2017. Whole Blood Donation Affects The Interpretation of Hemoglobin. USA. Baylor College of Medicine.

Blood donor selection. Guidelines on assessing donor suitability for blood donation. Annex 3. Geneva: World Health
Organization; 2012. [17 August 2012].

Joseph et all. 2015. Oral Iron Suplementation After Blood Donation. USA. Journal Of The American Medical Association.

Mast Alan. 2015. Low hemoglobin deferral in blood donors. National Center of Biotechnology Information (NCBI). 2015. Jan; 28(1): 18-22.

Meurrens Julie, Steiner Thomas, Ponette Jonathan, Janssen Hans, Ramaekers Monique, Wehrlin Jon Peter,Vandekerckhove Philippe, Deldicque Louise. 2016. Effect of Repeated Whole Blood Donations on Aerobic Capacity and Hemoglobin Mass in Moderatelym Trained Male Subjects: A Randomized Controlled Trial. Sports Medicine - Open (2016) 2:43.

Potgeisser Torben, Specker Wolfgang, Umhau Markus, Dickhuts Hans Herman, Roecker Kai. O York, Schumacer. 2008. Recovery of hemoglobin mass after blood donation. The Journal Of Transfussion Vol (48) Issue (7).

Spencer Bryan R. , Johnson Bryce , Wright David J. , Kleinman Steven, Simone A.Glynn, Ritchard G. 2017. Potential Impact on Blood Availability and Donor Iron Status of Cahnges to Donor Hemoglobin Cutoff and Interdonation Interval. Transfusion. 2016 August ; 56(8): 1994-2004. doi:10.1111/trf.13663.

Sudipta. 2016. Effect of Repeated Whole Blood Donation on Aerobic Capacity and Hemoglobin Mass In Moderately Trained Male Subject; RCT. NCBI Journal. 